Available from: https://thewire.in/tech/epidemic-diseases-actpersonal-details

15. HT Correspondent. Police crackdown on Covid-19 'misinformation' activists concerned. Hindustantimes.com. 2020 Apr 30[cited 2020 Oct 8]. Available from: https://www.hindustantimes.com/india-news/ about-500-cases-lodged-in-india-for-social-media-posts-on-covid-19/ story-PBaxt7oNs9ldPNUCVRiUUM.html

16. Mahaprashasta AA. Outrage as Adityanath govt uses Epidemic Diseases Act to arrest CAA dissenter. Wire.in. 2020 Mar 27[cited 2020 Oct 8]. Available from: https://thewire.in/rights/ashish-mittalepidemic-act-uttar-pradesh

17. Rabi MA. Social worker assaulted by cop, booked under Epidemic Act. Indianexpress.com. 2020 May 5[cited 2020 Oct 8]. Available from: https://www.newindianexpress.com/states/tamil-nadu/2020/may/13/ social-worker-assaulted-by-cop-booked-under-epidemic-act2142693.html

18. Subramaniam L. 4 booked in TN for violating home quarantine, could face up to 3.5 years in jail. Week.in. 2020 Mar 25[cited 2020 Oct 8]. Available from: https://www.theweek.in/news/india/2020/03/25/4booked-in-tn-for-violating-home-quarantine-could-face-up-to-35years-in-jail.html.

19. Thirumurthy P. SimpliCity website founder booked under Epidemic Diseases Act in Coimbatore. Newsminute.com. 2020 Apr 24[cited 2020 Oct 8]. Available from: https://www.thenewsminute.com/article/ simplicity-website-founder-booked-under-epidemic-diseases-actcoimbatore-123230. [Cited on October 8, 2020]

20. Dsouza DD, Quadros S, Hyderabadwala ZJ, Mamun MA, Aggregated COVID-19 suicide incidences in India: Fear of COVID-19 infection is the prominent causative factor. Psychiatry Res. 2020; 290: 113145

21. Thakker T. Covid-19 spread: Poor conditions of quarantine facilities come into focus in India. Economictimes.indiatimes.com. 2020 Mar 21[cited 2020 Oct 8]. Available from: https:// economictimes.indiatimes.com/news/politics-and-nation/poorconditions-of-quarantine-facilities-come-into-focus/articleshow/ 74738682.cms.

22. Parthasarathy S. Privacy concerns during a pandemic. Hindu.com. [newspaper on the internet]. 2020 Apr 29[cited 2020 Oct 8. Available from: https://www.thehindu.com/opinion/op-ed/privacy-concernsduring-a-pandemic/article31456602.ece.

23. Kattakayam JJ. When contact tracing becomes policing. The Times of India. [newspaper on the internet] 2020 Aug 20[cited 2020 Oct 8]. Available from: https://timesofindia.indiatimes.com/blogs/jibberjabber/when-contact-tracing-becomes-policing/.

24. Scroll Staff. Coronavirus: Hundreds booked across states for violating restrictions amid lockdown. Scroll.in. 2020 Mar 24[cited 2020 Oct 8] Available from: https://scroll.in/latest/957080/coronavirus-hundredsbooked-across-states-for-violating-restrictions-amid-lockdown.

25. Correspondent. Lockdown violation in Poonthura; people begins protest on street. Mathrubhoomi.com. 2020 Jul 10[cited 2020 Oct 8]. Available from: english.mathrubhumi.com/news/kerala/lockdownviolation-in-poonthura-people-begins-protest-on-streets-1.4894876

26. Sanjeev D. Gulf, Mumbai returnees feel stigmatised. Timesofindia.indiatimes.com. 2020 May 16[cited 2020 Oct 8]. Available from: http://timesofindia.indiatimes.com/articleshow/75765172.cms? utm_source=contentofinterest\&utm_medium =text\&utm_campaign $=$ cppst.

27. Parasthe G. Anandnagar rises in protest against containment, cops use force to quell it. Punemirror.indiatimes.com. 2020 Jun 09[cited 2020 Oct 8]. Available from: https://punemirror.indiatimes.com/pune/civic/ anandnagar-rises-in-protest-against-containment-cops-use-force-toquell-it/articleshow/76270964.cms.

28. Ramakrishnan S. In Madurai, people reluctant to test now: Doc. Timesofindia.indiatimes.com. 2020 Sep 30 [cited 2020 Oct 8]. Available from: http://timesofindia.indiatimes.com/articleshow/78395321.cms? utm_source=contentofinterest\&utm_medium=text\&utm_campaign= cppst.

29. American Association for the International Commission of Jurists. Siracusa Principles on the Limitation and Derogation of Provisions in the International Covenant on Civil and Political Rights (1984) (Annex, UN Doc E/CN.4/1984/4)[cited 2020 Oct 8]. Available from: https:// www.icj.org

\title{
Covid-19 vaccine trials and ethics: Protection delayed is protection denied
}

\author{
T JACOB JOHN, DHANYA DHARMAPALAN
}

\section{Abstract}

The Covid-19 pandemic is raging, taking a heavy toll of lives and livelihoods. The need for safe and effective vaccine(s) is urgent. Vaccine research has progressed rapidly and a few vaccine candidates have passed trial Phases 1 and 2, confirming reasonable safety and immunogenicity parameters. They are ready for large scale Phase 3 trials to quantify protective efficacy, if any, and to detect uncommon but serious adverse effects, if any.

Author: T Jacob John (tjacobjohn@yahoo.co.in), Retired Professor, Christian Medical College, Vellore, Tamil Nadu 632002 INDIA; Dhanya Dharmapalan (corresponding author - drdhanyaroshan@gmail.com), Consultant in Pediatric Infectious Diseases, Apollo Hospitals, CBD Belapur, Navi Mumbai. Maharashtra, INDIA.

To cite: John TJ, Dharmapalan D. Covid-19 vaccine trials and ethics. Indian J Med Ethics. 2021 Jan-Mar; 6(1) NS: 17-20. DOI:10.20529/ IJME.2020.104.

Published online first on October 24, 2020.

Peer Reviewers: Two anonymous peer reviewers

(c) Indian Journal of Medical Ethics 2020
These developments present unprecedented opportunities and challenges, scientific and ethical. Globally hundreds die every day due to Covid-19, and emergency/compassionate use of vaccine candidates that are ready for Phase 3 trials are likely to save lives. We perceive an ethical imperative to allow such an vaccination for those at high risk of death who voluntarily make such informed choice "for them protection delayed will be tantamount to protection denied.

Keywords: Covid-19, vaccine, vaccine trials, emergency use

\section{Introduction}

During the relentless march of the Covid-19 pandemic, globally we have faced the unprecedented problem of the highly contagious SARS coronavirus-2 (SARS-CoV-2) spreading like influenza. The world is prepared for an influenza pandemic, with global networks of laboratories in every continent constantly collecting virus strains, for the detection of any genetically shifted virus capable of seeding a 
pandemic. The vaccine platform is available and well-oiled. Add the new virus, and we get a new vaccine. When a genetic drift is detected in influenza viruses, vaccines are modified and tailor-made, annually.

To prevent deaths and reduce severe disease, we need a safe and effective Covid vaccine urgently, and vaccination is the ideal solution. If a vaccine is available after the epidemic is over, that is still good; but if one can be fast-tracked by revisiting the rules of trials, and vaccine can be made available while the epidemic is still raging, that would be best.

For registration by any National Drugs Regulatory Agency, a vaccine candidate must go through three phases of clinical trial testing. There are several vaccine candidates that have completed Phase 1 and 2 and are moving into Phase 3. In a Phase 1 trial, the vaccine candidate is given to a small number of healthy volunteers to determine if the product is welltolerated and non-toxic - i.e without serious adverse effects - any medical event that makes the subject sick enough for hospitalisation, or is life-threatening. In Phase 2 studies, a larger group of volunteers is exposed to the vaccine to further document side effects and monitor immunological responses. These Phases do not require a placebo control arm. A Phase 3 trial involves a very large number of subjects, and is placebo controlled and double blinded. The purpose is to check by what frequency the vaccine protects against disease and death, if it does so. Rare adverse reactions, if any, can also be detected.

\section{Scientific and ethical questions in a crisis situation}

Can pre-defined immunological parameters documented in Phase 2 trials be used as an interim protective surrogate for offering the vaccine under trial, to those who desire it and are willing to take the twin risks of rare serious adverse reaction and failure of a vaccine to protect against disease? This is, at once, a scientific and ethical question. If the regulatory agency allows this step, anticipating protection, the vaccine can be allowed in individuals at high risk of severe disease and death, without interfering with the Phase 3 trial. This may be qualified as emergency or compassionate use.

Who should be eligible for this option? Healthcare workers, particularly those above 55 years, individuals with co-morbidities, and anyone above 65 years, could be considered eligible. Vaccine may be offered strictly on voluntary application, with informed consent and declaration of no liability for the manufacturer or vaccinator. In order not to inter fere with the epidemiology of infection in locations where a Phase 3 trial is conducted, emergency use of vaccine must not be allowed in the catchment area of study volunteers.

\section{Debatable nature of the Russian and Chinese approaches}

Our purpose in this paper is to explore whether such a procedure would be ethical. The basic principles of medical ethics are non-maleficence, beneficence, justice and autonomy (1). While vaccine candidates are undergoing the traditional trial phases in western countries and India, Russia announced the temporary registration of a vaccine in the second week of August, valid until January 1, 2021 (2). The available published report mentioned 76 subjects being given vaccine during Phase 1 and 2 trials (3). The purpose, as stated in the media, was to make the vaccine available to healthcare workers, while Phase 3 trial continued - illustrating the process we have described above. The Russian decision came under severe criticism from scientists in and outside Russia, as no data on Phases 1 and 2 were initially made available in the public domain. Was it unethical in spite of the caveats that registration was temporary, only to allow 'emergency' use in selected target subjects, and to be revoked if Phase 3 results turned out unfavourable?

Meanwhile, China vaccinated an undisclosed number of military personnel, overseas workers and all staff of the vaccine manufacturing company, without registering it (4). The ethical questions are similar to those raised in Russia, but the additional ethical issue was the bypassing of the National Regulatory Agency in a public health vaccination programme.

The Covid-19 pandemic is causing a humanitarian crisis; and we believe we need to sail right through these unchartered ethical waters, carrying the vaccine as cargo. There are ethical implications in even a day's delay, as that might make the difference between the life and death and of numerous individuals vulnerable to severe COVID-19 disease and a high risk of death.

What are the ethical requirements for a vaccine under testing to be released to at-risk individuals who understand and accept the realities of incomplete information on safety and efficacy? The rules regarding trials in three phases apply under ordinary circumstances when the need for a vaccine is not as urgent as it is now.

\section{History revisited}

Ervobo, an experimental Ebola vaccine not having undergone Phase 3 trial, was, by consensus of all involved parties, directly applied during the Ebola outbreak in Guinea in early 2015, without placebo control (5). During the raging epidemic, with an over $40 \%$ death rate, local leaders wanted the vaccine with no one given placebo; and public health experts concurred. A novel design was accepted by all.Ebola cases were documented: in one set, all persons in contact with cases were immediately vaccinated. In another set, all contacts were vaccinated 21 days after case confirmation. None in the former group developed Ebola, while many in the second group did. As soon as the results were available, the vaccine was declared suitable for widespread application. Later, in 2019, with more data, Ervobo was approved by the European Commission and the United States Food and Drug Administration (6). The World Health Organization ( WHO) had concluded in 2014, that there was an "ethical imperative to offer available experimental 
interventions that have shown promising results in the laboratory, to people at high risk"(7).

Covid-19 is not Ebola, which has a $50-80 \%$ case fatality rate (8). However, Covid-19 does have relatively high death rates in the elderly and in those with co-morbidities. A systemic review and meta-analysis on Covid 19 reported an infection fatality rate (IFR) of $0.68 \%(0.53-0.82 \%)(9)$. This IFR may vary from country to country based on the population dynamics of age and co- morbidity. Preventing death is not the sole goal: survivors of severe disease are prone to debilitating chronic morbidity. Vaccine candidates offering safety from serious adverse reactions, and the ability to induce laboratory markers of immunity -- virus neutralising antibodies and T-cell immunity are already available; and the question is about an ethical imperative to allow its use pending registration. This is the challenge for the regulatory agencies in every country.

During World War 2, influenza was a threat to the health and life of US soldiers in the European theatre. An Influenza Commission was established which created an inactivated virus vaccine, tested in lab animals first and then in soldiers themselves. With positive results not yet published or made available to peer scientists, the vaccine was registered, manufactured, and used with remarkable success. Peace-time procedures were bypassed in war-time. The intentions were altruistic; the science impeccable; the dramatis personae were Jonas Salk and Thomas Francis.

\section{Beneficence and non-maleficence}

For a Phase 3 trial study volunteers are selected on the basis of criteria like age (between 18 and 60), health, and with no history of Covid or SARS-CoV-2 infection. If healthy adults can be given the candidate vaccine under coded condition of placebo versus vaccine, is there any additional harm or risk posed to individuals who are priority candidates for protection, once the vaccine is registered? For example, Guillain-Barre Syndrome (GBS) was detected as one case in about 1 lakh population when the influenza vaccine was administered in 1976 (10). However, there is data to show a higher risk of getting GBS due to viral influenza infection than to the vaccine. When the anticipated swine flu epidemic did not materialise in the US in 1976, the increase in GBS cases stood out, but it could not be attributed to an unethical decision: the vaccine had been approved by the USFDA for human use.

Regarding Covid vaccine, a benefit is theoretically present, and if the trial confirms protective efficacy, these out-oftrial vaccinees have already started enjoying the benefit of protection. If the trial concludes that the vaccine is not protective, no harm has been done either, unless there is a side-effect that has not been picked up in Phase 1 or 2 studies. Moreover, during the parallel Phase 3 trial, any unexpected but serious adverse effect would be known immediately and the trial halted until its safety is cleared. Similarly, the emergency use of vaccine must also be halted.
When there is reasonable evidence of protection and absence of harm, delaying the use of vaccine for those in urgent need of protection is the "moral dilemma" in our current context. We believe that beneficence and non-maleficence are satisfied in this situation

Do intentions matter? When scientists or vaccine companies take a vaccine candidate forward, and if the disease is endemic, the intention could be a mixture of altruism, scientific satisfaction/credit and/or profit motive. Under those circumstances, vaccine trials are the best option for protection of the public from undue haste to market a product which may have safety or efficacy problems. In the middle of the Covid pandemic, the motive ought to be to offer protection to the vulnerable and to control the epidemic, than to seek financial profit.

\section{Autonomy and justice}

Autonomy is ensured by requiring voluntary application, accepting all risks for probable benefit. The principle of justice is satisfied as a high priority of probable protection is offered to the vulnerable population. In summary, we see no ethical impediments in the emergency use of a vaccine that has cleared Phases 1 and 2 and is already in, or ready for, Phase 3 trials. On the contrary, we feel that strict adherence to the rule requiring the completion of Phase 3 trials and vaccine registration, while formally ethical, may actually be contrary to the spirit of ethics, as the lives and health of many could be protected by the principle of emergency use. The Covid case fatality rate (CFR) in India is about $1-2 \%$. We are not aware of any other respiratory transmitted disease, barring measles in under-five children with such high CFR. Therefore there is a strong case for allowing the emergency use of any Covid vaccine that is already in Phase 3 or is ready for Phase 3 trials.

\section{Conflict of interests: None declared}

\section{References}

1. Beauchamp TL, Childress JF, editors. Principles of biomedical ethics. 5th ed. New York: Oxford University Press; 2001.

2. Haidar S, Koshy J. Russian COVID-19 vaccine; Sputnik V is safe and effective, says RDIF CEO. The Hindu. 2020 Aug 20 [cited 2020 Sep 12]. Available from https://www.thehindu.com/news/national/russian- cov id-1 9- va cci ne -sp utn ik- v-i s- safe -an d-e ffec t ive -say s- rdif -ceo / article32400451.ece.

3. Logunov DY, Dolzhikova IV, Zubkova OV, Tukhvatullin A, Shcheblyakov D, Dzarullaeva A, et al. Safety and immunogenicity of an rAd26 and rAd5 vector-based heterologous prime-boost COVID-19 vaccine in two formulations: two open, non-randomised phase 1/2 studies from Russia.Lancet. 2020 Sep 3; S0140-6736(20)31866-3. doi:10.1016/ S0140-6736(20)31866-3.

4. Basu M. All you need to know about CanSino's Covid vaccine approved for military use in China. The Print. 2020 Jun 30 [cited 2020 Sep 12]. Available from https://theprint.in/health/all-you-need-to-know-aboutcansinos-covid-vaccine-approved-for-military-use-in-china/451554/.

5. Rid A, Miller FG. Ethical rationale for the Ebola "Ring Vaccination" tria design. Am J Public Health. 2016 Mar; 106(3): 432-5.

6. US Food and Drug Administration. First FDA-approved vaccine for the prevention of Ebola virus disease, marking a critical milestone in public health preparedness and response. 2019 Dec 19 [cited 2020

Sep 12]. Available from:https://www.fda.gov/news-events/pressannouncements/first-fda-approved-vaccine-prevention-ebola-virusdisease-marking-critical-milestone-public-health

7. World Health Organization.Ethical considerations for use of 
unregistered interventions for Ebola viral disease. 2014 [cited 2020 Sep 12]. Available from: https://apps.who.int/iris/bitstream/handle/ 10665/130997/WHO

HIS_KER_GHE_14.1_eng.pdf;jsessionid=F5243DBA1AE4803013A83AF 6D1FFF051? sequence $=1$

8. Wing K, Oza S, Houlihan C, Glynn GR, Irvine S, Warren CE, et al. Surviving Ebola: A historical cohort study of Ebola mortality and survival in Sierra Leone 2014-2015. PLoS One. 2018 Dec 27;13(12): e0209655.
9. Meyerowitz-Katz G, Me rone L. A systematic review and meta-analysis of published research data on COVID-19 infection-fatality rates. Int J Infect Dis. 2020 Sep 29; S1201-9712(20)32180-9. doi:10.1016/j. ijid. 2020.09.1464.

10. US Centers for Disease Control and Prevention (CDC). Guillain-Barré Syndrome and vaccines. Washington, USA: CDC; 2018 [cited 2020 Sep 12]. Available from::https://www.cdc.gov/vaccinesafety/concerns/ guillain-barre-syndrome.html.

\title{
Emergency use authorisation of Covid-19 vaccines: An ethical conundrum
}

\author{
VIPIN M VASHISHTHA, PUNEET KUMAR
}

\begin{abstract}
Largescale vaccination with a safe and effective vaccine against Covid19 is the only way to conquer the ongoing lethal pandemic that has led to extraordinary social and economic upheaval globally. Fortunately, the world is on the verge of developing Covid19 vaccines in an unprecedentedly short time. More than forty vaccines are in different stages of clinical trials, and a few are in the crucial phase III studies stage. A new demand for emergency use authorisation and rapid deployment of these vaccines before scrutinising phase III trial data is raging in different quarters. Can advancement of the deployment of these vaccines by even a few weeks give us rich public health dividends? Would it be ethical to deploy these novel vaccines based only on the safety and immunogenicity data generated by the phase I and II clinical trials? Would it be ethical to deny vaccination of vulnerable populations against an untreatable infectious disease despite the availability of reasonably safe and efficacious vaccines for the want of phase III trial data? The answer is not straightforward, as there are many complexities involved. This commentary attempts to discuss some ethical issues involved in a decision to deploy Covid19 vaccination before phase III trial results are declared.
\end{abstract}

Keywords: Covid19, vaccine candidates, bioethics, clinical trials, emergency use

Author: Vipin M Vashishtha (vipinipsita@gmail.com), Director and Consultant Paediatrician, Department of Paediatrics, Mangla Hospital and Research Centre, Shakti Chowk, Bijnor 246701 Uttar Pradesh INDIA; Puneet Kumar (info@KumarChildClinic.com), Clinician, Kumar Child Clinic, KM Chowk, Sector 12, Dwarka, New Delhi, INDIA.

To cite: Vashishtha M V, Kumar P. Emergency use authorisation of Covid-19 vaccines: An ethical conundrum. Indian J Med Ethics. 2021 Jan-Mar; 6(1) NS: 20-22. DOI: 10.20529/IJME.2020.122.

Published online first on November 26, 2020.

( I) Indian Journal of Medical Ethics 2020

\section{Background}

The Severe Acute Respiratory Syndrome Coronavirus type-2 (SARS-CoV-2) pandemic has caused great social and economic upheaval globally. Nearly ten months into the pandemic, hopes of conquering Covid-19 still rest largely on the production of a vaccine. Thanks to the unprecedented speed and scale of development, more than forty candidates are now in advanced stages of clinical trials. Yet whether vaccines will meet our hopes for a return to normal-now, or in the years to come-will depend on our ability to meet a new kind of challenge, one as logistical, operational, and cultural as it is epidemiological, and far more complex than any the world has faced in the history of immunisation to date. Adding further complexity to the existing issues is a new demand for allowing emergency use authorisation of Covid-19 vaccines before completion of the full phase III trials, which poses a new ethical challenge (1). Would it be ethical to deny vaccination to a vulnerable population against an untreatable infectious disease despite the availability of reasonably safe and efficacious vaccines for the want of phase III trial data? Would advancing the deployment of safe and effective vaccine(s) by even a few weeks provide rich public health dividends? This new ethical dilemma has posed a formidable challenge.

\section{Applying the four principles of bioethics}

Would it be ethical to deploy the Covid-19 vaccine(s) based on safety and immunogenicity data generated by phase-I and II clinical trials alone, without waiting for the crucial phase-III trials? The answer is not straightforward, as many complexities are involved. The issue needs to be deliberated in detail to see if the four basic principles of bioethics (respect for autonomy, non-maleficence, beneficence, and justice) (2) are satisfied. If any Covid-19 vaccine is deployed without waiting for the phase-III trial data, and vaccination is carried out after obtaining the full informed consent of the vaccinees, there should not be any violation of the principle of respect for autonomy. Non-maleficence (do no harm) is a crucial component of bioethics principles that needs careful 